\title{
Dermacoccus barathri sp. nov. and Dermacoccus profundi sp. nov., novel actinomycetes isolated from deep-sea mud of the Mariana Trench
}

Correspondence Michael Goodfellow m.goodfellow@ncl.ac.uk

\author{
Wasu Pathom-aree, ${ }^{1} \dagger$ Yuichi Nogi, ${ }^{2}$ Alan C. Ward, ${ }^{1}$ Koki Horikoshi, ${ }^{2}$ \\ Alan T. Bull ${ }^{3}$ and Michael Goodfellow ${ }^{1}$ \\ ${ }^{1}$ Division of Biology, University of Newcastle, Newcastle upon Tyne NE1 7RU, UK \\ ${ }^{2}$ Extremobiosphere Research Center, Japan Agency for Marine-Earth Science and Technology \\ (JAMSTEC), 2-15 Natsushima-cho, Yokosuka 237-0061, Japan \\ ${ }^{3}$ Department of Biosciences, University of Kent, Canterbury, Kent CT2 7NJ, UK
}

The genus Dermacoccus Stackebrandt et al. 1995 currently contains two species, Dermacoccus nishinomiyaensis (Oda 1935) Stackebrandt et al. 1995, a taxon that comprises strains initially classified as Micrococcus nishinomiyaensis Oda 1935 emend. Kocur et al. 1975, and Dermacoccus abyssi Pathom-aree et al. 2006a that accommodates a piezotolerant strain isolated from sediment collected from the Challenger Deep in the Mariana Trench. The genus Dermacoccus is classified in the family Dermacoccaceae Stackebrandt and Schumann 2000, together with the genera Demetria Groth et al. 1997 and Kytococcus Stackebrandt et al. 1995; isolates assigned to this family are typically associated with terrestrial habitats, notably cured meat products, skin and soil (Cordero \& Zumalacárregui, 2000; De la Rosa et al., 1990; Papamanoli et al., 2002).

The present investigation was designed to determine the taxonomic status of two additional actinobacterial strains that were isolated from the Challenger Deep and were found

tPresent address: Department of Biology, Faculty of Science, Chiang Mai University, Chiang Mai 50200, Thailand.

The GenBank/EMBL/DDBJ accession numbers for the 16S rRNA gene sequences of strains MT2.1 $1^{\top}$ and $M T 2.2^{\top}$ are AY894328 and AY894329, respectively. to be closely related to Dermacoccus abyssi (Pathom-aree et al., 2006a). The isolates were the subjects of a polyphasic study, which showed that they merited classification as representing novel Dermacoccus species, Dermacoccus barathri sp. nov. and Dermacoccus profundi sp. nov.

Strains MT2.1 $1^{\mathrm{T}}$ and MT2. $2^{\mathrm{T}}$ were isolated from a sediment sample collected from the Mariana Trench (Challenger Deep; $11^{\circ} 19^{\prime} 911^{\prime \prime} \mathrm{N} 142^{\circ} 12^{\prime} 372^{\prime \prime} \mathrm{E}$ ) at a depth of $10898 \mathrm{~m}$ using sterilized mud samplers and the remotely operated submersible Kaiko (Kato et al., 1997). The sample (2 ml), which was collected on 21 May 1998 during dive number 74, was transported to the UK in an insulated container at $4{ }^{\circ} \mathrm{C}$ and then stored at $-20{ }^{\circ} \mathrm{C}$. The strains were isolated from a suspension of the sediment sample used to inoculate a raffinose-histidine agar plate (Vickers et al., 1984) supplemented with cycloheximide and nystatin. The isolates were maintained on glucose-yeast extract agar plates (Gordon \& Mihm, 1962) at room temperature and as glycerol suspensions $(20 \%, \mathrm{v} / \mathrm{v})$ at $-20^{\circ} \mathrm{C}$. Biomass for the chemotaxonomic and molecular systematic studies was prepared from 7-day-old glucose-yeast extract broth (Gordon \& Mihm, 1962) shake cultures grown at $28^{\circ} \mathrm{C}$, washed twice with distilled water and harvested by centrifugation. 
Isolation of chromosomal DNA, PCR amplification and direct sequencing of the purified products of strains MT2.1 ${ }^{\mathrm{T}}$ and MT2.2 $2^{\mathrm{T}}$ were carried out as described previously (Pathom-aree et al., 2006b). Almost-complete 16S rRNA gene sequences of isolates MT2.1 ${ }^{\mathrm{T}}$ (1468 nt) and MT2.2 ${ }^{\mathrm{T}}$ (1466 nt) were aligned manually with corresponding sequences of representatives of genera classified in the suborder Micrococcineae that had been retrieved from the DDBJ/EMBL/GenBank databases using the program PHYDIT (available at http://plaza.snu.ac.kr/ jchun/phydit/). Phylogenetic trees were inferred using the leastsquares (Fitch \& Margoliash, 1967), maximum-likelihood (Felsenstein, 1981), maximum-parsimony (Kluge \& Farris, 1969) and neighbour-joining (Saitou \& Nei, 1987) treemaking algorithms from the PHYLIP suite of programs (Felsenstein, 1993). Evolutionary distance matrices for the least-squares and neighbour-joining methods were generated after Jukes \& Cantor (1969). The stability of the resultant tree topologies were evaluated by bootstrap analysis (Felsenstein, 1985) based on 1000 resamplings of the neighbour-joining dataset using the SEQBOOT and CONSENSE options from the PHYLIP package.

It is evident from Fig. 1 that the isolates fall within the evolutionary radiation occupied by the genus Dermacoccus. The two strains shared a $16 \mathrm{~S}$ rRNA gene sequence similarity of $99.9 \%$, a value that corresponds to a single nucleotide difference at the 1470 locations available for comparison. It is evident from the phylogenetic tree that the isolates are most closely associated with the type strain of Dermacoccus abyssi, a relationship that was supported by all of the treemaking algorithms and by a $100 \%$ bootstrap value.

Isolates MT2. ${ }^{\mathrm{T}}$ and $\mathrm{MT} 2.2^{\mathrm{T}}$ were examined for key chemical markers to determine whether they had a chemotaxonomic profile consistent with their classification within the genus Dermacoccus. Standard methods were used for the extraction and analysis of fatty acids (Sutcliffe, 2000), mycolic acids (Hamid et al., 1993), isoprenoid quinones (Collins, 1994), muramic acid type (Uchida et al., 1999) and polar lipids (Minnikin et al., 1984) from freeze-dried biomass of the isolates. The peptidoglycan structures of the cell walls of the strains were determined by the DSMZ identification service using established procedures (Schleifer \& Kandler, 1972; Schleifer, 1985; MacKenzie, 1987).

The two isolates were found to have a chemotaxonomic profile consistent with their classification in the genus Dermacoccus (Stackebrandt et al., 1995; Pathom-aree et al., 2006a). They were also characterized by the presence of $\mathrm{N}$ acetylated muramic acid, L-lysine as the diamino acid, diphosphatidylglycerol, phosphatidylglycerol and phosphatidylinositol as major polar lipids (phospholipid type I sensu Lechevalier et al., 1977), dihydrogenated menaquinones with eight isoprene units as the predominant isoprenologue, fatty acids rich in branched-chain components and by the absence of mycolic acids.

One- and two-dimensional TLC of the total hydrolysate of the peptidoglycan of each strain $\left(4 \mathrm{M} \mathrm{HCl}, 16 \mathrm{~h}\right.$ at $\left.100{ }^{\circ} \mathrm{C}\right)$ showed the presence of the amino acids alanine, glutamic acid, lysine and serine. After derivatization, the molar amino acid ratios as determined by gas chromatography were $3 \cdot 0$ Ala, 0.9 Ser, $2.3 \mathrm{Glu}, 1 \cdot 0$ Lys and a trace of Thr for strain MT2. $1^{\mathrm{T}}$ and $3 \cdot 2 \mathrm{Ala}, 0 \cdot 1 \mathrm{Thr}, 0 \cdot 9 \mathrm{Ser}, 2 \cdot 4 \mathrm{Glu}$ and $1 \cdot 0$ Lys for strain MT2. $2^{\mathrm{T}}$. Traces of hydrolytically stable peptide were also found for each strain (Lys-Ser). Partial hydrolysis (4 M $\mathrm{HCl}, 45 \mathrm{~min}$ at $100^{\circ} \mathrm{C}$ ) and two-dimensional TLC showed the presence of the peptides L-Ala-D-Glu, D-Ala-D-Glu, LLys-L-Ser, D-Ala-L-Lys-L-Ser; the patterns were identical for each strain. Denitrophenylation showed that the glutamic acid was from the $\mathrm{N}$ terminus of the interpeptide bridge. It is evident from these data that the strains have an A4 $\alpha$ peptidoglycan type sensu Schleifer \& Kandler (1972).

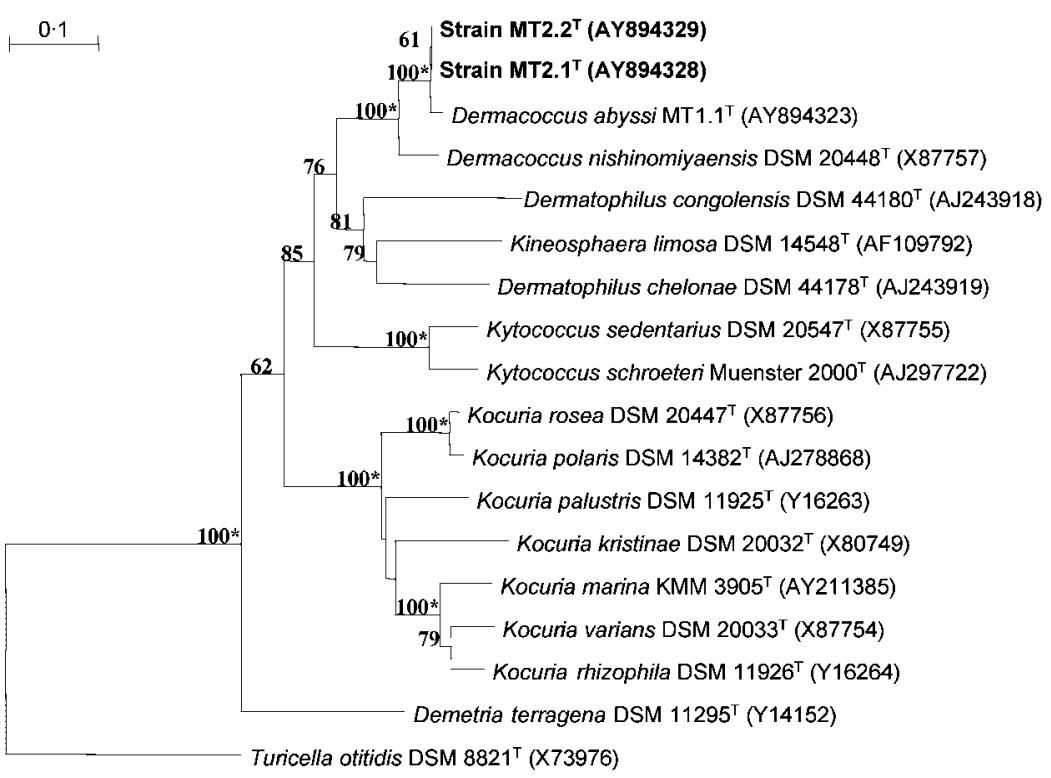

Fig. 1. Neighbour-joining tree (Saitou \& Nei, 1987) based on almost-complete $16 \mathrm{~S}$ rRNA gene sequences showing the relationships between isolates MT2.1 $1^{\top}$ and $\mathrm{MT} 2.2^{\top}$ and representatives of the suborder Micrococcineae. Asterisks indicate phyletic lines that were recovered using the leastsquares (Fitch \& Margoliash, 1967), maximumlikelihood (Felsenstein, 1981) and maximumparsimony (Kluge \& Farris, 1969) tree-making algorithms. Numbers at nodes indicate levels of bootstrap support based on a neighbourjoining analysis of 1000 resampled datasets; only values above $50 \%$ are given. Bar, $0 \cdot 1$ substitutions per nucleotide position. 
The fatty acids of the two strains were very similar and notably rich in branched-chain components ( $>40 \%$ total in each; 13-methyltetradecanoic, 14-methylpentadecanoic, 15-methylhexadecanoic and 14-methylhexadecanoic acids). Saturated straight-chain components $(20-24 \%$ total; hexadecanoic, heptadecanoic and octadecanoic acids) and unsaturated straight-chain components $(29-36 \%$ total; hexadecenoic, heptadecenoic and octadecenoic acids) were also present; each strain also contained a trace of 12methyltetradecanoic acid (anteiso-15), probably as a byproduct of anteiso- $\mathrm{C}_{17: 0}$ fatty acid synthesis. The fatty acid profiles were very similar to those reported previously for Dermacoccus abyssi NCIMB $14084^{\mathrm{T}}$ (Pathom-aree et al., 2006a). As discussed previously with respect to our analyses of fatty acid composition in Dermacoccus abyssi NCIMB $14084^{\mathrm{T}}$ and Dermacoccus nishinomiyaensis DSM $20448^{\mathrm{T}}$ (Pathom-aree et al., 2006a), we did not detect significant quantities of branched-chain unsaturated fatty acids in isolates MT2.1 ${ }^{\mathrm{T}}$ and MT2.2 $2^{\mathrm{T}}$, although these have previously been reported in Dermacoccus nishinomiyaensis and Kytococcus spp. (Stackebrandt et al., 1995; Becker et al., 2002). Aside from our findings, anteiso- $C_{15: 0}$ was not found to be a major fatty acid for Dermacoccus nishinomiyaensis (Stackebrandt et al., 1995) or for close relatives such as Demetria terragena (Groth et al., 1997), Dermatophilus congolensis (McNabb et al., 1997) or Kineosphaera limosa (Liu et al., 2002). In contrast, Kytococcus schroeteri and Kytococcus sedentarius contain minor proportions of this component ( 3.5 and $1.2 \%$, respectively; Stackebrandt et al., 1995; Becker et al., 2002) and Kocuria species significant proportions (approximately 50-70\%; Stackebrandt et al., 1995; Kovács et al., 1999; Schumann et al., 1999).
The G+C contents of the DNAs of isolates MT2.1 ${ }^{\mathrm{T}}$ and MT2. $2^{\mathrm{T}}$ were determined by reversed-phase HPLC (Tamaoka \& Komagata, 1984); an equimolar mixture of four deoxyribonucleotides in a Yamasa GC kit (Yamasa Shoyu) was used as the quantitative standard. DNA-DNA hybridization experiments were carried out between the two isolates and between them and Dermacoccus abyssi DSM $17573^{\mathrm{T}}$ and Dermacoccus nishinomiyaensis DSM $20448^{\mathrm{T}}$ using the microplate method, as described by Ezaki et al. (1989). Mean percentage DNA-DNA relatedness values were calculated from three hybridization experiments. The DNA G $+\mathrm{C}$ contents of isolates MT2.1 ${ }^{\mathrm{T}}$ and MT2.2 ${ }^{\mathrm{T}}$ were $66 \cdot 8$ and $69 \cdot 1 \mathrm{~mol} \%$, respectively. The mean DNA-DNA relatedness found between the two isolates was $17 \cdot 6 \pm 6 \cdot 5 \%$, a value well below the $70 \%$ cut-off point recommended for the assignment of bacterial strains to the same genomic species (Wayne et al., 1987). Similarly, isolates MT2.1 ${ }^{\mathrm{T}}$ and MT2.2 ${ }^{\mathrm{T}}$ had DNA-DNA relatedness values with the type strains of Dermacoccus abyssi and Dermacoccus nishinomiyaensis of $14 \cdot 3 \pm 4 \cdot 7$ and $24 \cdot 6 \pm 8 \cdot 9 \%$, and $4 \cdot 3 \pm 2 \cdot 5$ and $14 \cdot 6 \pm 3 \cdot 5 \%$, respectively.

The two organisms were examined for a range of biochemical and physiological characteristics using methods described by Kloos et al. (1974); Williamsia marianensis DSM $44944^{\mathrm{T}}$ was used as a positive control for the acid from carbohydrate tests. The two isolates and the type strains of Dermacoccus abyssi and Dermacoccus nishinomiyaensis were screened for enzyme activity using API ZYM kits (bioMérieux); the results were read after $4 \mathrm{~h}$ at $30^{\circ} \mathrm{C}$. It is apparent from Table 1 that the two isolates can be distinguished from one another and from the type

Table 1. Phenotypic properties that differentiate isolates $M T 2.1^{\top}$ and $M T 2.2^{\top}$ from one another and from the type strains of Dermacoccus abyssi and Dermacoccus nishinomiyaensis

+ , Positive, - , negative.

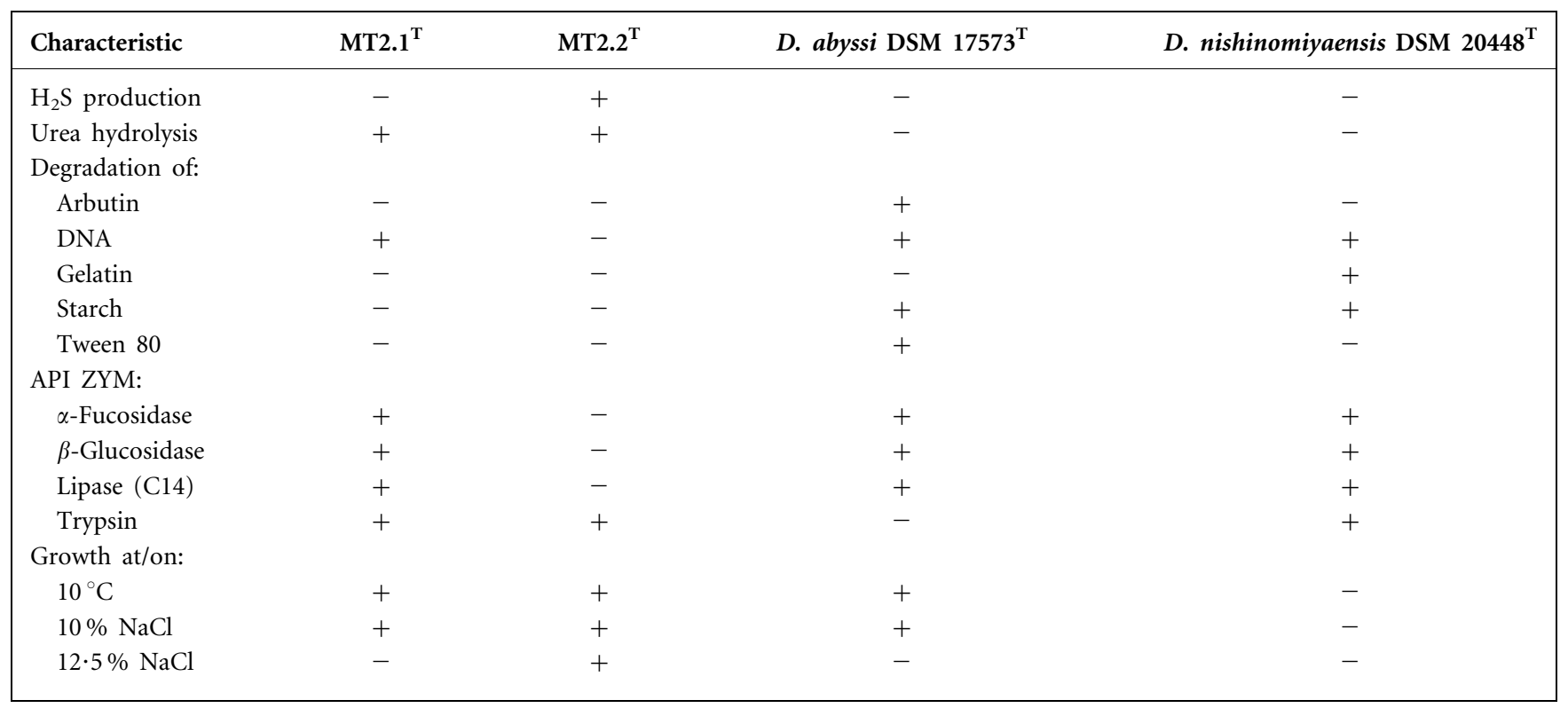


strains of Dermacoccus abyssi and Dermacoccus nishinomiyaensis by a range of phenotypic properties. It is particularly interesting that only the strains isolated from the Challenger Deep sediment grew at $10{ }^{\circ} \mathrm{C}$ and in the presence of high salt concentrations. The close taxonomic relationship found between the dermacocci isolated from the Mariana Trench sediment suggest that isolates MT2.1 $1^{\mathrm{T}}$ and MT2. $2^{\mathrm{T}}$ will prove to be piezotolerant, as Dermacoccus abyssi DSM $17573^{\mathrm{T}}$ grows well at $40 \mathrm{MPa}$ (Pathom-aree et al., 2006a).

The genotypic and phenotypic data show that isolates MT2.1 $1^{\mathrm{T}}$ and MT2.2 ${ }^{\mathrm{T}}$ represent novel species within the genus Dermacoccus. The names proposed for these taxa are Dermacoccus barathri sp. nov. and Dermacoccus profundi sp. nov.

\section{Description of Dermacoccus barathri sp. nov.}

Dermacoccus barathri (ba.ra'thri. L. neut. n. barathrum a deep pit, an abyss; L. gen. n. barathri of an abyss).

Aerobic, Gram-positive, non-acid-alcohol-fast, non-motile actinomycete that forms coccoid cells (diameter $0 \cdot 8-1 \cdot 5 \mu \mathrm{m})$ that occur in irregular clusters. Light-yellow, circular, entire, convex, smooth, glistening colonies are formed on glucose-yeast extract agar after 5 days at $28^{\circ} \mathrm{C}$. Grows well on tryptic soy agar, but poorly on inorganic nitrogen agar. Growth occurs between 10 and $37^{\circ} \mathrm{C}$, with an optimum around $28^{\circ} \mathrm{C}$. Hypoxanthine, Tween 20, Tween 40 and uric acid are degraded. Acid is not formed from $(+)$-Darabinose, (+)-D-arabitol, (-)-L-arabitol, (+)-D-cellobiose, dextran, meso-erythritol, (+)-D-fructose, $(+)$-Dgalactose, $(+)$-D-glucose, glycerol, glycogen, myo-inositol, inulin, (+)-D-maltose, $(+)$-D-mannitol, $(+)$-D-mannose, $(+)$-D-melezitose, (+)-D-melibiose, $\quad(+)$-D-raffinose, $(-)$-L-rhamnose, $(+)$-D-salicin, (+)-D-sucrose, (+)-Dtrehalose, $(+)$-D-sorbitol, ( + )-L-sorbose, xylitol or ( + )-Dxylose. Additional phenotypic properties are shown in Table 1. Has chemical markers characteristic of the genus Dermacoccus.

The type strain is MT2.1 ${ }^{\mathrm{T}}\left(=\mathrm{DSM} \quad 17574^{\mathrm{T}}=\mathrm{NCIMB}\right.$ $14081^{\mathrm{T}}$ ), which was isolated from sediment collected from the Challenger Deep of the Mariana Trench at a depth of $10898 \mathrm{~m}$. The $\mathrm{G}+\mathrm{C}$ content of the DNA of the type strain is $66 \cdot 8 \mathrm{~mol} \%$.

\section{Description of Dermacoccus profundi sp. nov.}

Dermacoccus profundi (pro.fun'di. L. neut. n. profundum depth, abyss; L. gen. n. profundi of an abyss).

Aerobic, Gram-positive, non-acid-alcohol-fast, non-motile actinomycete that forms coccoid cells (diameter $0 \cdot 8-1.5 \mu \mathrm{m})$ that occur in irregular clusters. Brilliantyellow, irregular, entire, pulvinate, rough colonies with matted surfaces are formed on glucose-yeast extract agar after 5 days at $28^{\circ} \mathrm{C}$. Grows well on tryptic soy agar, but poorly on inorganic nitrogen agar. Growth occurs between
10 and $37^{\circ} \mathrm{C}$, with an optimum around $28^{\circ} \mathrm{C}$. Hypoxanthine, Tween 20, Tween 40 and uric acid are degraded. Acid is not formed from $(+)$-D-arabinose, $(+)$ D-arabitol, (-)-L-arabitol, (+)-D-cellobiose, dextran, meso-erythritol, $(+)$-D-fructose, $(+)$-D-galactose, $(+)$-Dglucose, glycerol, glycogen, myo-inositol, inulin, $(+)$-Dmaltose, (+)-D-mannitol, (+)-D-mannose, $(+)$-D-melezitose, $(+)$-D-melibiose, (+)-D-raffinose, (-)-L-rhamnose, (+)-D-salicin, (+)-D-sucrose, $(+)$-D-trehalose, $(+)$-D-sorbitol, (+)-L-sorbose, xylitol or $(+)$-D-xylose. Additional phenotypic properties are shown in Table 1. Has chemical markers characteristic of the genus Dermacoccus.

The type strain is $\mathrm{MT} 2.2^{\mathrm{T}}\left(=\mathrm{DSM} \quad 17575^{\mathrm{T}}=\mathrm{NCIMB}\right.$ $\left.14084^{\mathrm{T}}\right)$, which was isolated from sediment collected from the Challenger Deep of the Mariana Trench at a depth of $10898 \mathrm{~m}$. The $\mathrm{G}+\mathrm{C}$ content of the DNA of the type strain is $69 \cdot 1 \mathrm{~mol} \%$.

\section{Acknowledgements}

Wasu Pathom-aree is grateful to the DPST program and the Royal Thai Government for financial support. We thank the Kaiko operation team and the crew of MS Yokosuka for collecting the sediment samples, Dr Iain Sutcliffe (University of Northumbria) for help with the fatty acid analyses, Amanda Jones (University of Newcastle) for carrying out the API tests and Dr Jean Euzéby for expert advice in naming the organisms. This work was supported by the UK Natural Environmental Research Council (grants NER/T/S/2000/00614 and NER/T/S/2000/ 00616). Alan Bull thanks The Leverhulme Trust for the award of an Emeritus Fellowship.

\section{References}

Becker, K., Schumann, P., Wüllenweber, J., Schulte, M., Weil, H.-P., Stackebrandt, E., Peters, G. \& von Eiff, C. (2002). Kytococcus schroeteri sp. nov., a novel Gram-positive actinobacterium isolated from a human clinical source. Int J Syst Evol Microbiol 52, 16091614 .

Collins, M. D. (1994). Isoprenoid quinones. In Chemical Methods in Prokaryotic Systematics, pp. 265-309. Edited by M. Goodfellow \& A. G. O’Donnell. Chichester: Wiley.

Cordero, M. R. \& Zumalacárregui, J. M. (2000). Characterization of Micrococcaceae isolated from salt used for Spanish dry-cured ham. Lett Appl Microbiol 31, 303-306.

De la Rosa, M. C., Mohino, M. R., Mohino, M. \& Mosso, M. A. (1990). Characteristics of micrococci and staphylococci isolated from semipreserved meat products. Food Microbiol 7, 207-215.

Ezaki, T., Hashimoto, Y. \& Yabuuchi, E. (1989). Fluorometric deoxyribonucleic acid-deoxyribonucleic acid hybridization in microdilution wells as an alternative to membrane filter hybridization in which radioisotopes are used to determine genetic relatedness among bacterial strains. Int J Syst Bacteriol 39, 224-229.

Felsenstein, J. (1981). Evolutionary trees from DNA sequences: a maximum likelihood approach. J Mol Evol 17, 368-376.

Felsenstein, J. (1985). Confidence limits on phylogenies: an approach using the bootstrap. Evolution 39, 783-791.

Felsenstein, J. (1993). PHYLIP (phylogeny inference package), version 3.5c. Department of Genome Sciences, University of Washington, Seattle, USA. 
Fitch, W. M. \& Margoliash, E. (1967). Construction of phylogenetic trees. Science 155, 279-284.

Gordon, R. E. \& Mihm, J. M. (1962). Identification of Nocardia caviae (Erikson) nov. comb. Ann N Y Acad Sci 98, 628-636.

Groth, I., Schumann, P., Rainey, F. A., Martin, K., Schuetze, B. \& Augsten, K. (1997). Demetria terragena gen. nov., sp. nov., a new genus of actinomycetes isolated from compost soil. Int $J$ Syst Bacteriol 47, 1129-1133.

Hamid, M. E., Minnikin, D. E., Goodfellow, M. \& Ridell, M. (1993). Thin-layer chromatographic analysis of glycolipids and mycolic acids from Mycobacterium farcinogenes, Mycobacterium senegalense and related taxa. Zentralbl Bakteriol 279, 354-367.

Jukes, T. H. \& Cantor, C. R. (1969). Evolution of protein molecules. In Mammalian Protein Metabolism, vol. 3, pp. 21-132. Edited by H. N. Munro. New York: Academic Press.

Kato, C., Li, L., Tamaoka, J. \& Horikoshi, K. (1997). Molecular analyses of the sediment of the 11,000-m deep Mariana Trench. Extremophiles 1, 117-123.

Kloos, W. E., Tornabene, T. G. \& Schleifer, K. H. (1974). Isolation and characterization of micrococci from human skin, including two new species: Micrococcus lylae and Micrococcus kristinae. Int J Syst Bacteriol 24, 79-101.

Kluge, A. G. \& Farris, F. G. (1969). Quantitative phyletics and the evolution of anurans. Syst Zool 18, 1-32.

Kocur, M., Schleifer, K. H. \& Kloos, W. E. (1975). Taxonomic status of Micrococcus nishinomiyaensis Oda 1935. Int J Syst Bacteriol 25, 290-293.

Kovács, G., Burghardt, J., Pradella, S., Schumann, P., Stackebrandt, E. \& Màrialigeti, K. (1999). Kocuria palustris sp. nov. and Kocuria rhizophila sp. nov., isolated from the rhizoplane of the narrow-leaved cattail (Typha angustifolia). Int J Syst Bacteriol 49, 167-173.

Lechevalier, H. A., De Biévre, C. \& Lechevalier, M. P. (1977). Chemotaxonomy of aerobic actinomycetes: phospholipid composition. Biochem Syst Ecol 5, 249-260.

Liu, W.-T., Hanada, S., Marsh, T. L., Kamagata, Y. \& Nakamura, K. (2002). Kineosphaera limosa gen. nov., sp. nov., a novel Grampositive polyhydroxyalkanoate-accumulating coccus isolated from activated sludge. Int J Syst Evol Microbiol 52, 1845-1849.

MacKenzie, S. L. (1987). Gas chromatographic analysis of amino acids as the N-heptafluorobutyryl isobutyl esters. J Assoc Off Anal Chem 70, 151-160.

McNabb, A., Shuttleworth, R., Behme, R. \& Colby, W. D. (1997). Fatty acid characterization of rapidly growing pathogenic aerobic actinomycetes as a means of identification. J Clin Microbiol 35, 1361-1368.

Minnikin, D. E., O’Donnell, A. G., Goodfellow, M., Alderson, G., Athalye, M., Schaal, A. \& Parlett, J. H. (1984). An integrated procedure for the extraction of isoprenoid quinones and polar lipids. J Microbiol Methods 2, 233-241.

Oda, M. (1935). Bacteriological studies on waters used for brewing saké (part 6). I. Bacteriological studies on "miyamizu" (8) and (9). Micrococcus and Actinomyces isolated from "miyamizu". Jozogaku Zasshi 13, 1202-1228 (in Japanese).
Papamanoli, E., Kotzekidou, P., Tzanetakis, N. \& LitopoulouTzanetaki, E. (2002). Characterization of Micrococcaceae isolated from dry fermented sausage. Food Microbiol 19, 441-449.

Pathom-aree, W., Nogi, Y., Sutcliffe, I. C., Ward, A. C., Horikoshi, K., Bull, A. T. \& Goodfellow, M. (2006a). Dermacoccus abyssi sp. nov., a novel piezotolerant actinomycete isolated from the Mariana Trench. Int J Syst Evol Microbiol 56, 1233-1237.

Pathom-aree, W., Stach, J. E. M., Ward, A. C., Horikoshi, K., Bull, A. T. \& Goodfellow, M. (2006b). Diversity of actinomycetes isolated from Challenger Deep sediment $(10,898 \mathrm{~m})$ from the Mariana Trench. Extremophiles 10, 181-189.

Saitou, N. \& Nei, M. (1987). The neighbor-joining method: a new method for reconstructing phylogenetic trees. Mol Biol Evol 4, 406-425.

Schleifer, K. H. (1985). Analysis of the chemical composition and primary structure of murein. Methods Microbiol 18, 123-156.

Schleifer, K. H. \& Kandler, O. (1972). Peptidoglycan types of bacterial cell walls and their taxonomic implications. Bacteriol Rev 36, 407-477.

Schumann, P., Spröer, C., Burghardt, J., Kovacs, G. \& Stackebrandt, E. (1999). Reclassification of the species Kocuria erythromyxa (Brooks and Murray 1981) as Kocuria rosea (Flügge 1886). Int J Syst Bacteriol 49, 393-396.

Stackebrandt, E. \& Schumann, P. (2000). Description of Bogoriellaceae fam. nov., Dermacoccaceae fam. nov., Rarobacteraceae fam. nov. and Sanguibacteraceae fam. nov. and emendation of some families of the suborder Micrococcineae. Int J Syst Evol Microbiol 50, 1279-1285.

Stackebrandt, E., Koch, C., Gvozdiak, O. \& Schumann, P. (1995). Taxonomic dissection of the genus Micrococcus: Kocuria gen. nov., Nesterenkonia gen. nov., Kytococcus gen. nov., Dermacoccus gen. nov., and Micrococcus Cohn 1872 gen. emend. Int J Syst Bacteriol 45, 682-692.

Sutcliffe, I. C. (2000). Characterisation of a lipomannan lipoglycan from the mycolic acid containing actinomycete Dietzia maris. Antonie van Leeuwenhoek 78, 195-201.

Tamaoka, J. \& Komagata, K. (1984). Determination of DNA base composition by reverse-phase high-performance liquid chromatography. FEMS Microbiol Lett 25, 125-128.

Uchida, K., Kudo, T., Suzuki, K. I. \& Nakase, T. (1999). A new rapid method of glycolate test by diethyl ether extraction, which is applicable to a small amount of bacterial cells of less than one milligram. J Gen Appl Microbiol 45, 49-56.

Vickers, J. C., Williams, S. T. \& Ross, G. W. (1984). A taxonomic approach to selective isolation of streptomycetes from soil. In Biological, Biochemical and Biomedical Aspects of Actinomycetes, pp. 553-561. Edited by L. Ortiz-Ortiz, L. F. Bojalil \& V. Yakoleff. Orlando: Academic Press.

Wayne, L. G., Brenner, D. J., Colwell, R. R. \& 9 other authors (1987). International committee on Systematic Bacteriology. Report of the ad hoc committee on reconciliation of approaches to bacterial systematics. Int J Syst Bacteriol 37, 463-464. 